\title{
Relations between perceived teacher's autonomy support, cognitive appraisals and boredom in physics learning among lower secondary school students
}

\author{
Margaret Ekatushabe ${ }^{1^{*}}$ (D) Diana Kwarikunda ${ }^{2}$, Charles M. Muwonge ${ }^{1}$, Joseph Ssenyonga ${ }^{1,3}$ and Ulrich Schiefele ${ }^{2}$
}

\begin{abstract}
Background: Boredom during learning activities has the potential of impeding attention, motivation, learning and eventually achievement. Yet, research focusing on its possible antecedents seems to have received less attention especially within the physics domain. Based on assumptions of the Control Value Theory of Achievement Emotions (CVTAE), this study aimed at examining gender differences and structural relationships between students' reported perceived teacher autonomy support (PTAS), cognitive appraisals (self-efficacy and task value) and learning-related boredom in physics. A sample of 375 (56\% females) randomly selected $9^{\text {th }}$ grade students (mean age $=15.03$ years; $S D=1.02)$ from five secondary schools in Masaka district of Uganda took part in the study.

Results: Data collected from students' self-reports using standardised instruments revealed that higher levels of PTAS, self-efficacy, and task value were significantly associated with lower levels of boredom during physics learning. Females reported significantly greater task value for learning physics than the males. Self-efficacy $(\beta=$ $-.10, p<.05)$ and task value $(\beta=-.09, p<.01)$ partially mediated the relationship between PTAS and boredom. PTAS showed significant direct negative contributions to boredom $(\beta=-.34, p<.001)$.

Conclusion: These findings provide support for theory and practice about the importance of promoting autonomy among students by adjusting instructional behaviours among teachers of physics. Teacher autonomy supportive behaviours influence formation of students' beliefs about ability, subjective value and learning-related boredom in physics. Implications and suggestions for further research are also discussed in this paper.
\end{abstract}

Keywords: Teacher autonomy support, Cognitive appraisals, Self-efficacy, Task value, Boredom, Gender, Physics

\section{Introduction}

The advancement in Science, Technology, Engineering and Mathematics (STEM) through science education is key for socio-economic expansion within developing countries. Although efforts in most developing African countries are being made towards STEM improvement by focusing on education, their performance still lags

\footnotetext{
* Correspondence: margaretekatushabe@gmail.com

'Department of Educational Foundations and Psychology, Faculty of Science, Mbarara University of Science and Technology, P. O. Box 1410, Mbarara, Uganda

Full list of author information is available at the end of the article
}

compared to the rest of the world (Arvanitis, Waast, \& Gaillard, 2000; Pouris \& Pouris, 2009). This concern about the consistent low performance in STEM disciplines however is also still an issue for many developed countries as it may impede further development. Studies have linked poor performance in STEM subjects to psychological factors including poor attitudes; high achievement anxiety; low interest and motivation, lack of enjoyment, low task value and self-efficacy; and others (Kiwanuka et al., 2017; Muwonge, Ssenyonga, \& Kwarikunda, 2018; Opolot-Okurut, 2005) that rapidly increase 
during the early high school years (Patall, Dent, Oyer, \& Wynn, 2013; Reid \& Skryabina, 2003).

Also, the consistent gender gaps in physical sciences achievement favouring males continue to be an issue of discussion. Further, compared to males, fewer females are normally willing to undertake physics-related careers and courses at a higher level even when they qualify for them (Goan, Cunningham, \& Carroll, 2006; Seba, Ndunguru, \& Mkoma, 2013; Sikora \& Pokropek, 2012). These gender gaps have been especially attributed to psychological factors of subjective value and control that are shaped by the social environment (Eccles, 2011).

Current research stemming from Pekrun's (2006) Control Value Theory of Achievement Emotions (CVTAE) focuses on the antecedents and effects of achievement emotions (Liu et al., 2018; Muwonge et al., 2018; Wang et al., 2017). Of particular concern is the relationship between these emotions and students' perceptions of control and value of the learning activities, that are often structured by the social environment. Among the studies conducted in STEM disciplines, those focusing on mathematics highly dominate (Lazarides \& Buchholz, 2019; Liu et al., 2018; Muwonge et al., 2018; Wang et al., 2017). However, unlike the widely studied test anxiety, other negative emotions like boredom and its potential antecedents remain relatively unexplored (Pekrun, Goetz, Daniels, Stupinsky, \& Perry, 2010). Learningrelated boredom is a negative emotion characterized by feelings of low arousal, unpleasantness, dullness, constraint, and repetitiveness experienced during performance of a task (Larson \& Richards, 1991). Hence, a student who feels bored by the learning activity is likely to (1) show no desire to participate in the activity, (2) feel unreasonably tired while dealing with the activity and (3) perceive the activity's material as dull or monotonous (Mulligan \& Scherer, 2012; Pekrun et al., 2010). Boredom is a common experience during learning activities that are thought to have no value and are difficult (Pekrun, 2006). In Uganda, where learning physics at lower secondary is compulsory and not dependent on perceived ability or interest, boredom is quite likely among students. Previous studies associated high occurrences of boredom among students with low autonomy support received from significant others like the teachers. Teacher autonomy-supportive behaviours relate to the interpersonal behaviours that promote a learner's "sense of unpressured willingness to engage in learning" (Deci, Ryan, \& Williams, 1996, p.1). They include providing choice, providing a meaningful rationale for learning certain material, listening to students' views, expressing perspective-taking, responding appropriately to students' concerns, allowing students to work independently, acknowledging negative affect and providing students opportunities to work on activities that interest them (Patall et al., 2013). Boredom and its effects among students have been linked to learning environments where the teachers offer high emotional, social and autonomy support (Tze, Klassen, \& Daniels, 2014; Wang et al., 2017). However, among the STEM domains, studies seem to focus more on the mathematics domain and rarely on physics despite the reported domain specificity of achievement emotions (Goetz, Cronjager, Frenzel, Ludtke, \& Hall, 2010; Pekrun et al., 2010). Further, the few known studies on gender differences in teacher autonomy support, cognitive appraisals (i.e. self-efficacy and task value) and boredom in physics learning in addition to being based on studies in a few developed countries, also present mixed findings with some studies finding differences, that favour the males and others finding no differences at all (Limprecht, Janko, \& GlaserZikuda, 2013; Pekrun, Goetz, Frenzel, Barchfeld, \& Perry, 2011; Piko \& Pinczes, 2015; Sierens et al., 2010; Tucker et al., 2002; Vansteenkiste et al., 2012).

Although there is evidence to confirm that boredom can be beneficial in stimulating creativity, this creativity will normally be focused on another task irrelevant to the task at hand (Schubert, 1978). Studies have found that when learners find a task boring, their performance in that task is negatively affected (Haager, Kuhbandner, \& Pekrun, 2016; Pekrun et al., 2010). Boredom impedes the learners' abilities to effectively channel their cognitive resources into accomplishing such tasks being considered as boring. This way, their attention, engagement, motivation, self-regulation and use of learning strategies are compromised which affect achievement (Pekrun, 2006; Pekrun et al., 2010). The meta-analysis by Tze, Daniels, and Klassen (2015) found that boredom experienced during lessons rather than that experienced during studying was more negatively associated with motivation, use of learning strategies and achievement among students. Also, the effects of learning-related boredom have been studied in many contexts. In all cases, the general findings project boredom as impeding learning and achievement (Sanchez-Rosas \& Esquivel, 2016; Tze et al., 2014; Tze et al., 2015; Wang et al., 2017).

Knowing the potential impact of boredom, a clear understanding of the role of learning environmental factors in shaping learners' emotional experiences may be a crucial step in ensuring better student achievement in STEM domains. For example, boredom has been associated with several external factors shaped by teachers, parents and peers (like the quality of instruction, reinforcement, parental expectations and support and peer attitudes) that later translate into several internal beliefs about control and value (Pekrun, 2006). Often, if these external factors are gender-biased, then the resulting cognitive beliefs and emotions present variations 
based on gender. Further, even after controlling for achievement, females experience more boredom and low subjective control in physical science domains than males (Goetz, Frenzel, Hall, \& Pekrun, 2008). Knowing the associations of perceived teacher autonomy support (PTAS) with cognitive appraisals and boredom especially as they shape gender differences can be helpful in further understanding the gender gap in STEM. Hence, this study sought to explore the gender differences and nature of relationships between perceived teacher autonomy support, cognitive appraisals and boredom during physics learning among lower secondary school students in Uganda. The findings of this study provide not just physics teachers but also those individuals involved in teacher training valuable information regarding instructional practices to improve students' self-efficacy, guide students into valuing physics and reduce boredom in the physics classroom for students at the lower secondary school level. This may also apply to other STEM disciplines. Understanding the role of gender in students' self-reported self-efficacy, task value, perceived teacher autonomy support and boredom in physics also provides important information that may help design instruction to reduce the gender gap in STEM achievement. Besides, the study provides empirical evidence for support of some assumptions of the CVTAE (Pekrun, 2006) across the Ugandan cultural context.

\section{Physics education in Uganda}

Physics is learnt as one of the compulsory STEM subjects (including biology, chemistry and mathematics) with in the first 4 years (that is $8^{\text {th }}$ to the $11^{\text {th }}$ year of formal schooling) of lower secondary school education. At the advanced secondary school level (that is $12^{\text {th }}$ and $13^{\text {th }}$ year of formal schooling), studying physics is optional and students can choose to do it in combination with other subjects such as mathematics, chemistry and economics among others. However, the decision to study physics at this level may also be either influenced by the school based on an individual's previous performance at the ordinary level or by the parental preferences. At the end of each secondary school level, learners sit national examinations and results obtained from these examinations provide the basis for entry to higher levels.

For many learners, learning physics at lower secondary is not a choice but rather a means to fulfill curriculum requirements whether the learners consider themselves capable of succeeding in physics and/or whether they value physics or not. Perhaps this explains some of the reasons why most learners tend to obtain low grades in STEM domains at national examinations. Furthermore, the choice to offer physics at an advanced level is mostly based on the role of the subject in helping learners attain substantial grades to qualify for various programs at university, and rarely is this choice a matter of sheer interest in the discipline. To incentivise secondary students to select physics, the government invests more resources in science through government sponsorship to students offering physics-related programs at the tertiary level and subsequently better wages for scientific professions and future employment opportunities. Hence, there are extrinsic sources of motivation for taking on physics beyond the ordinary secondary level. These incentives have been made even more available for female scientists. For example, following persistent low numbers of females in science careers, in 1990, a government policy was passed that awards each female an extra 1.5 points when competing for government scholarships into tertiary institutions. Despite the above efforts, physics has remained the worst-performing science subject in the final examination at lower secondary school in Uganda since 2015 (Uganda National Examinations Board, 2015, 2016, 2017, 2018). Besides, the wider gender gap favouring males than females in STEM domains still exists as evidenced in the national examination results.

Further, the learning environment in most Ugandan secondary schools is predominantly teacher-centred. This is especially attributed to inadequate teacher training on effective teaching practices, inadequate teaching and learning resources, high student-teacher ratios and increases teacher workload that limit time for effective lesson preparation (Black et al., 1998; Bwire, Huang, Masingila, \& Ayot, 2011). Uganda is a developing country, socio-economic levels could be thought of a likely cause of learners' negative attitudes and low motivation in STEM. However, Kiwanuka, Van Damme, Van Den Noortgate, Anumendem, and Namusisi's (2015) study found that classroom climate, parental support and previous mathematics achievement and not the socioeconomic status of students significantly influenced achievement. Further, Kiwanuka et al. (2017) in an effort to try and understand the relationship between the social environment and psychological attributes found that learners who reported more enjoyment of and greater self-confidence in mathematics also perceived teacher's behaviour to promote more classroom interaction through questioning and modeling through supporting learners in developing their way of handling math tasks without the need for constant directions from the teacher. Researchers have found that learner-related variables like low motivation, low self-efficacy, low task value and poor attitudes towards science to be associated with low achievement in STEM (See Muwonge et al., 2018; Opolot-Okurut, 2005). Hence, the teachinglearning environment mostly structured by teacher behaviours towards learners influences learners' classroom experiences that eventually structure their cognitive 
appraisals and emotional experiences. However, research efforts to link teachers' behaviours particularly autonomy support to negative learning-related emotions like boredom in Uganda are non-existent despite low achievement that has been linked through several studies to boredom.

In the following sections, we discuss the literature related to the study beginning with the theoretical framework, followed by a description of cognitive appraisals and then relationships between the study variables, before describing the present study's methodology.

\section{Theoretical framework-the control value theory of achievement emotions}

The hypotheses of this study were largely grounded in the assumptions of the CVTAE (Pekrun, 2006). Achievement emotions relate to emotional experiences either due to being part of certain learning activities and/or their outcomes (such as boredom or enjoyment during a lesson, hope to succeed in a test, anxiety during a test). The theory explains the distal (social environment) and proximal (cognitive appraisals) antecedents of achievement emotions and the effects of these emotions on learning and achievement (Fig. 1).

Particularly, achievement emotions are directly influenced by an individual's cognitive appraisals of perceived control and value related to the activity or its outcomes (anticipated or realised). The structuring of a learner's cognitive appraisals influences the development of particular achievement emotions (Pekrun, 2006). For example, a student's lack of value in the task being learnt coupled with either extremely low or extremely high perceived control in the same task results in experiences of boredom during learning well as a combination of high subjective value and control results in enjoyment of the same learning task (Pekrun et al., 2011). Achievement emotions are also influenced by the social environment either directly or indirectly through their effect on cognitive appraisals (Pekrun, 2006; Pekrun \& Stephens, 2010). Indirectly, students' perceived classroom environments mostly structured by peers, parents and teachers that communicate control and value influence the development of different achievement emotions (Frenzel, Pekrun, \& Goetz, 2007b). For example, teachers who often communicate the rationale for learning certain concepts or topics promote learners' subjective value which makes learners feel more interested while engaged in learning such concepts. Alternatively, different teacher behaviours can directly result in different emotional experiences within a student (Robinson, 1975). Teachers who express enthusiasm facilitate learners to enjoy or develop an interest in a subject unlike those who express no such enthusiasm (Goetz, Pekrun, Hall, \& Haag, 2006).

Different achievement emotions have varying influences on the learning and achievement of students. Commonly, negative emotions (e.g. anxiety, boredom and hopelessness) and positive emotions (e.g. enjoyment, pride, relief and hope) have negative and positive effects respectively. Pekrun, Goetz, Titz, and Perry (2010) observed that positive emotions of enjoyment, pride and hope in general were positively correlated with students'; interest, motivation, task effort, use of effective learning strategies and perceived self-regulation; and negatively correlated with task-irrelevant thinking, perceived external learning-related regulation and achievement. For most of the negative emotions particularly boredom and hopelessness, their effects were generally reversed. These findings have been confirmed by several other studies (Pekrun et al., 2010; Sanchez-Rosas \& Esquivel, 2016; Tze et al., 2015).

\section{Cognitive appraisals}

Cognitive appraisals relate to the internally held beliefs of an individual about the value of and their control over certain tasks or situations (Pekrun, 2006). Subjective control cognitions may either be prospective as in the case of self-efficacy (the belief in one's ability to adequately perform a given task as may be expected; Bandura, 1977), focusing on how current abilities relate to

The model illustrating the CVTAE

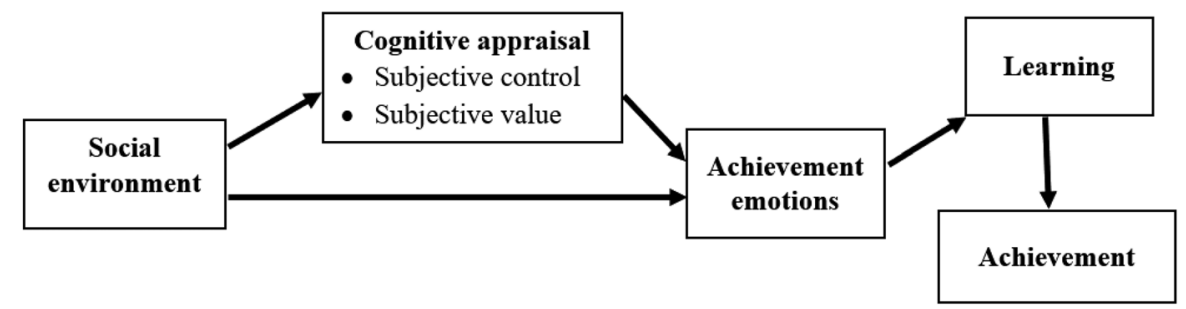

Note. Adapted from Pekrun (2006)

Fig. 1 The model illustrating the CVTAE. Adapted from Pekrun (2006) 
future outcomes or retrospective as in causal attributions focusing on reasons for certain outcomes. For example, a learner may attribute present test success to either luck, hard work or intelligence or a combination of any of such reasons. The adapted pattern of perceived attributional causes has an impact on their motivational and emotional state. Also, students with high self-efficacy express confidence about their abilities to succeed in future physics tasks like tests or classroom exercises. Constructs like self-confidence, perceived competence or ability, self-efficacy and self-concept in a domain reflect a certain component of subjective control of an individual (Skinner, 1996). Subjective value or task value as used in this study relates to the perceived importance attached to a task and/or its potential outcomes (Eccles \& Wigfield, 1995). Task value can be either extrinsic being motivated by external factors like anticipated attainment of a job in the future, or intrinsic, with the value derived from internal resources of interest in the activity not dependent on anticipated long-term goals (Putwain et al., 2018). For example, a student who considers learning physics as highly valuable attaches great importance in understanding the material, is interested and enjoys learning physics-related material and/or considers it to be beneficial in achieving other related long-term goals like a physics-related career.

\section{Cognitive appraisals and boredom}

According to Pekrun (2006), the relationship between perceived control and boredom is curvilinear. Hence, boredom will likely occur if a learner either feels significantly over-challenged or significantly under-challenged by the task demands which in both cases the learner will likely withdraw their cognitive resources (Acee et al., 2010). Although this is logically reasonable, most studies have noted a linear relationship (Pekrun et al., 2010; Putwain et al., 2018). For example, Pekrun et al. (2010) revealed a linear relationship between subjective control and boredom. This relation was attributed to the nature of achievement situations in the learning setting that will most often present some level of challenge even to the high ability students who represent a small number of learners in a class. For STEM subjects at any given grade level, it is likely that the majority of the students will often find the tasks to be either over-challenging or moderately challenging but rarely under-challenging. In fact, studies confirm that high perceived control and ability shield learners from boredom (Fogelman, 1976; Kanevsky \& Keighley, 2003; Robinson, 1975).

Studies conducted in academic settings suggest a negative linear association between cognitive appraisals and boredom. Hence, a learner is most likely to feel bored by the learning activity if they feel considerably incapable of succeeding in it and do not consider it to be of much value to their present or future life. This negative association has been confirmed in different contexts including China (Liu et al., 2018; Wang et al., 2017), Germany (Goetz et al., 2006; Pekrun et al., 2010), North America (Pekrun et al., 2010), Argentina (Sanchez-Rosas \& Esquivel, 2016) and England (Putwain et al., 2018).

\section{Teacher autonomy support and cognitive appraisals}

As postulated in the CVTAE, the development of cognitive appraisals may be influenced by the social environment created by teachers. Particularly, autonomysupportive teacher behaviours in the classroom structure learners' perceptions about their control and value of the tasks being learnt. These behaviours eventually have a significant bearing on the psychological functioning of the learner in the classroom especially concerning what they believe they are capable of doing on their own and how valuable they perceive what they learn. Several studies focusing on STEM subjects especially within mathematics suggest that perceived teacher autonomy support is positively associated with students' control appraisals (Painter, 2011; Wang et al., 2017). Painter's (2011) study involving $8^{\text {th }}$ grade students $(n=6,946)$ from the USA found that students' perceived teacher autonomy support was negatively and indirectly associated with science achievement through their reported competence beliefs. The study also found that teacher autonomy support was the strongest predictor of students' perceived science competence. Different teacher autonomy-supportive behaviours directly or indirectly also influence the development of students' subjective value of the learning material (d'Ailly, 2003; Joussemet, Koestner, Lekes, \& Houlfort, 2004; Patall et al., 2013; Piko \& Pinczes, 2015; Ryan \& Grolnick, 1986). For instance, a study by Patall et al. (2013) among $9^{\text {th }}$ through $12^{\text {th }}$ graders in the USA noted that teacher behaviours like providing students with choices on how activities were run and engaging in perspective-taking were correlated to course value through autonomy-need satisfaction, whereas clear and reasonable communication of the importance or usefulness of the course material was directly correlated with course value. The association between teacher autonomy support and task value was especially stronger for students in lower grade levels than those in higher grade levels.

\section{Teacher autonomy support and boredom}

Correlational studies confirm that teacher autonomysupportive behaviors are negatively correlated with boredom and this relation operates at both individual and class levels (Tze et al., 2014). Goetz et al. (2013b) found that learners who perceived their teachers as demonstrating an effort to help them understand the material (like using easily understandable vocabulary and using 
illustration) were less likely to feel bored during physics lessons.

\section{Mediating effects of cognitive appraisals}

In line with the CVTAE, studies have confirmed the mediational role of cognitive appraisals on the relation between social environmental factors and achievement emotions (Goetz et al., 2006; Liu et al., 2018; SanchezRosas \& Esquivel, 2016; Wang et al., 2017). The study by Wang et al. (2017) among Chinese middle school students found cognitive appraisals to fully mediate the relationship between students' perceived teacher autonomy support and boredom in mathematics. The mediation effect was also found by Liu et al. (2018) who looked at autonomy support and positive emotions and Goetz et al. (2006) looking at parental influences on enjoyment and anxiety. In contrast, Sanchez-Rosas and Esquivel's (2016) study supported a partial mediation model where cognitive appraisals partially mediated the influence of instructional quality on boredom. Hence, it is unclear whether cognitive appraisals either fully or partially mediate the effects of the social envoronment on development of acheivement emotions.

The CVTAE's assumptions about the relationships among these variables have generally demonstrated universality across some cultures and contexts, between genders and among different subject domains (Goetz et al., 2008; Pekrun et al., 2010; Wang et al., 2017). However, most studies were conducted within the developed countries with a focus on the mathematics domain. These issues bring into question the generalisability of these findings to other domains like physics and other contexts especially within the low- and middle-income countries.

\section{Gender differences}

\section{Teacher autonomy support}

Due to previous general trends in achievement and occupational choices in STEM subjects that have been dominated by males, a false image about these disciplines as better suited for males has been created (Gunderson, Ramirez, Levine, \& Beilock, 2012; Nosek, Banaji, \& Greenwald, 2002). Hence, gender differences in several aspects of STEM education have been linked to gender stereotypes that influence parents' and teachers' behaviours towards different genders. Through their conscious and unconscious behaviour towards learners, teachers are in a strong position to provide learners with various kinds of information regarding their autonomy in learning a subject (Pekrun, 2006). Differential treatment of boys and girls especially in STEM education is evident in the literature (Gunderson et al., 2012). For example, teacher-student academic interactions tend to be biased in favour of males who generally receive more questions (often of higher-order) from the teacher (Altermatt, Jovanovic, \& Perry, 1998; Becker, 1981) and less non-academic positive feedback about performance compared to females. Also, questions raised by male students are given more attention compared to those raised by female students. Hence, males participate receive more learning attention, and therefore perceive more control in science classes than the females (Samuelsson \& Samuelsson, 2016).

On the other hand, some studies seem to find that females perceive a more favourable emotional support learning environment than males (Fisher, Fraser, \& Rickards, 1997; Goh \& Fraser, 1998). For example, in Fisher et al.'s (1997) study, females tended to perceive more helping, understanding and friendly tendencies from their science and mathematics teachers than the males. Females attach more value to receiving teacher emotional and appraisal support in the form of free sharing, expressing concern for their challenges, fair treatment and sensitive reactions to mistakes made (Tennant et al., 2014).

However, only a few recent studies have examined the influence of gender on perception of teacher behaviour in any of the STEM domains more commonly in mathematics (Ahmed, Minnaert, van der Werf, \& Kuyper, 2010; Gherasim, Butnaru, \& Mairean, 2013; Liu et al., 2018). Both Liu et al.'s study involving Chinese elementary and middle school students and Ahmed et al.'s study involving lower secondary Dutch students found no correlation between gender and perceived teacher support in Mathematics. These studies contradicted Gherasim et al. (2013) who found that females perceived their mathematics teachers to be more supportive than males. Other studies that have examined gender differences within the general classroom environment also found that females students reported higher levels of teacher autonomy support than the male students. For example, Vansteenkiste et al.'s (2012) study among $7^{\text {th }}$ through $13^{\text {th }}$ grade students $(n=1036)$ in Belgium found that females perceived their teachers' behaviours as being more autonomy-supportive than the males. This was consistent with a study in Belgium by Sierens et al. (2010) involving $11^{\text {th }}$ through $12^{\text {th }}$ graders $(n=526)$. On the contrary, the Hungarian study by Piko and Pinczes (2015) and the study by Tucker et al. (2002) among African American elementary and high school students $(n=109)$ showed no significant differences in PTAS. More recent STEM education literature on gender differences in TAS is however scarce and yet, it may be necessary for the understanding of the current trends in girls' and boys' experiences in STEM classroom environments. Knowing the association between autonomy support and cognitive 
appraisals, substantial gender variations in PTAS are likely to translate into gender variations in cognitive appraisals (Eccles, 2011; Pekrun, 2006).

\section{Cognitive appraisals}

Most research on gender differences in subjective control and value in STEM subjects point to variations that favour the males even after controlling for achievement levels (Goetz et al., 2008; Hyde, Fennema, Ryan, Frost, \& Hopp, 1990; Sikora \& Pokropek, 2012). The recent study by Nissen (2019) involving over 4816 high school students in the USA found that although both genders experienced low self-efficacy in physics and other science subjects, the girls still reported significantly lower levels of self-efficacy than the boys. Lower subjective control and value of mathematics was found among girls compared to boys. This relation was also found among German elementary mathematics students and become more pronounced from the second to the third grade (Lichtenfeld, Pekrun, Stupnisky, Reiss, \& Murayama, 2012). This gender gap is also consistent with other studies (Opolot-Okurut, 2005; Piko \& Pinczes, 2015). One particular study by Opolot-Okurut (2005) involving 254. (52\% females) Ugandan $9^{\text {th }}$ grade students found that the females were less confident about their mathematics skills than the males. These findings contradicted with a later larger study by Kiwanuka et al. (2017) involving Ugandan mathematics $7^{\text {th }}$ grade students $(n=$ $4819,55 \%$ females) and a recent study by Kwarikunda, Schiefele, Ssenyonga, and Muwonge (2020) involving Ugandan Physics $9^{\text {th }}$ grade students $(n=374,56 \%$ females) in which no significant gender differences in subjective control were reported. This study was also consistent with Majere, Role, and Makewa's (2012) study among Kenyan physics students. However, in both these studies, girls still viewed the subjects to be more useful than the boys did. In their study, Picho and Stephens (2012) examined the influence of communicated gender stereotypes on self-efficacy and achievement levels of $10^{\text {th }}$ grade mathematics female Ugandan students $(n=$ 89) who initially had approximately equal achievement levels from mixed-sex schools and single-sex schools. Results showed that females from the single-sex schools had significantly higher self-efficacy, identification with mathematics and achievement scores than those from the former schools. Verbal messages that communicated gender differences had a great influence on females' perception of ability. If such verbal messages are constantly communicated by significant others, then such beliefs are further reinforced.

\section{Boredom}

As is hypothesised in the CVTAE, gender differences in emotional experiences originate from differences among males and females in cognitive appraisals (Pekrun, 2006). Hence, according to the theory, the tendency for girls to feel low control and a lack of value over their learning results in more experiences of negative emotions than boys (Frenzel, Pekrun, \& Goetz, 2007a; Lichtenfeld et al., 2012). For example, Daschmann, Goetz, and Stupnisky (2011) found that males attributed their boredom in mathematics to being under-challenged and females to being over-challenged. These gender differences are consistent with studies that examined math anxiety-a commonly studied emotion (Else-Quest, Hyde, \& Linn, 2010; Goetz, Bieg, et al., 2013; Ma \& Cartwright, 2003). Also, intervention studies focusing on improvement of the instructional environment to regulate achievement emotions among female students have proved effective. For instance, in an intervention study with German $8^{\text {th }}$ grade $(n=161)$ students, females as compared to males initially reported higher levels of boredom which was linked to gender differences in self-concept and interest in the subject (Limprecht et al., 2013). However, after a portfolio intervention program involving physics instruction characterized by continuous teacher feedback, cooperation and self-reflection and self-regulation in learning, females' self-reports on boredom during instruction reduced in the treatment group after controlling for self-concept and interest. However, some nondomain-specific studies and those studies outside STEM domains seem to find no significant gender differences in boredom (Pekrun et al., 2011; Piko \& Pinczes, 2015) while others seem to find cross-cultural variations in gender differences (Lichtenfeld et al., 2012). While Lichtenfeld et al. found that within the German sample of elementary students, females reported low perceived control and high boredom, in the American sample, there were no significant differences among both females and males in perceived control and value but significant differences in boredom that favoured the males. Therefore, in addition to the studies on gender differences in boredom experienced during studying of STEM disciplines being scarce and contradictory, most of the findings on gender differences in learning-related boredom are based on studies in mathematics.

\section{The present study}

This study was aimed at finding out the gender differences and structural relationship between the study variables: teacher autonomy support, cognitive appraisals and boredom in physics learning. The following research questions and hypotheses guided the study:

1. Are there any significant correlations between students' perceived teacher autonomy support, cognitive appraisals and boredom? Based on previous research findings, we hypothesised that 
perceived teacher autonomy support would be positively correlated with cognitive appraisals and all of the variables would be negatively correlated with boredom.

2. Do males significantly differ from females in their self-reported perceived teacher autonomy support, cognitive appraisals and boredom in physics? Based on the findings from studies by Kiwanuka et al. (2017), Kwarikunda et al. (2020), Majere et al. (2012) and Sikora and Pokropek (2012), we tested the hypothesis that there were no significant gender differences in the study variables.

3. Is the relationship between perceived teacher autonomy support and learning-related boredom in Physics fully or partially mediated by cognitive appraisals? In line with the CVTAE (Pekrun, 2006) and several other studies, it was clear that cognitive appraisals had a mediating role in the relationship between PTAS and boredom. However, these studies presented mixed findings as to whether or not cognitive appraisals partially or fully mediated this relationship. We tested both full and partial mediation models in which perceived teacher autonomy support influences on boredom were either only indirect or both direct and indirect, i.e. through cognitive appraisals (see Fig. 2).

\section{Methods}

\section{Sampling and participants}

The target population was approximately $45009^{\text {th }}$ grade students from 31 mixed-sex day and boarding secondary schools in Masaka district, Uganda (Education policy and planning department, 2017). As recommended by Krejcie and Morgan (1970), the sample consisted of 375 students from five randomly selected schools. Proportionate random sampling based on gender resulted in a sample of $210(56 \%)$ females and 165 males (44\%). The age range of the participants was 13 to 19 years with a mean of 15.03 years $(S D=1.02)$. Some of the participants $(50.9 \%)$ were commuting from home and only attended school during the day with others (49.1\%) were residing at school.

\section{Study design and procedure}

The study employed a quantitative cross-sectional survey design. This implies that quantitative data was collected from a sample of randomly selected participants in only a one-time phase. Collecting data at a single time phase was well suited for our study purpose and was less timeconsuming. Before commencing data collection, ethical approval for the study was first obtained from Mbarara University of Science and Technology Research Ethics Committee. Then, we obtained permission to approach the selected schools and students from the Masaka District Education officer and school authorities respectively. We then visited the schools and explained to the school authorities and participants information regarding the purpose of the study, the significance of the study and the data collection and usage process. The sampled participants were informed of their right to confidentiality, informed consent and voluntary participation. The participants were allowed to ask any question(s) regarding the study before and during questionnaire administration. Selected students under the guidance of the researchers then filled the questionnaires during normal school time. All information collected was anonymous, remained confidential and was used for research purposes only.

\section{Instruments}

Data were collected using anonymous self-report questionnaires. The first section elicited socio-demographic data including gender, residence status and age. The next three sections were scales measuring perceived teacher autonomy support, cognitive appraisals and boredom adapted for physics learning. For each of these scales, the total score was obtained by adding up the corresponding item scores. The observed range of total scores and Cronbach alpha for each scale in the present study are represented in Table 1.

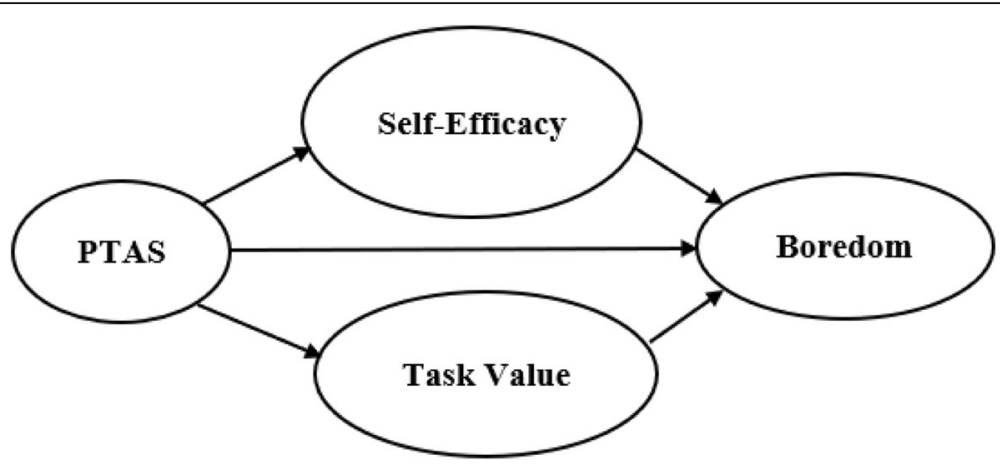

Fig. 2 The partial mediation model showing structural relationship between the study variables 
Table 1 Descriptive statistics, Cronbach alpha and correlation matrix for the study variables

\begin{tabular}{lllllll}
\hline Variables & $\boldsymbol{M}(\boldsymbol{S D})$ & Range & $\mathbf{1}$ & $\mathbf{2}$ & $\mathbf{3}$ & $\mathbf{4}$ \\
\hline 1. Perceived TAS & $76.65(17.76)$ & $15-105$ & $\mathbf{. 9 0}$ & & & \\
2. Self-efficacy & $14.85(4.14)$ & $0-20$ & $.47^{* *}$ & $\mathbf{. 7 8}$ & & \\
3. Task value & $33.63(7.50)$ & $6-42$ & $.33^{* *}$ & $.46^{* *}$ & $\mathbf{. 7 8}$ & \\
4. Boredom & $24.64(10.54)$ & $11-55$ & $-.47^{* *}$ & $-.39^{* *}$ & $-.36^{* *}$ & $\mathbf{. 9 0}$
\end{tabular}

TAS teacher autonomy support. Missing values excluded pairwise. ${ }^{* *} p<.01$. Corresponding Cronbach alphas for each scale in bold

Perceived teacher's autonomy support was measured using a 15-item measure adapted from the Williams and Deci's (1996) Learning Climate Questionnaire (LCQ; $\alpha=$ .91). Sample items on this scale included "I feel that my physics teacher provides me choices and options" and "my physics teacher shows confidence in my ability to do well in physics tests". The items were scored on a 7point Likert scale ranging from strongly disagree (1) to strongly agree (7).

Learning-related boredom was measured using an adapted 11-item Learning-Related Boredom Scale (LRBS; $\alpha=.82$; Pekrun et al., 2011). Students responded to the items on a five-point Likert scale ranging from 1 (strongly disagree) to 5 (strongly agree). Sample items included "Studying physics is dull and monotonous" and "While studying this boring physics material, I spend my time thinking of how time stands still."

Cognitive appraisals were measured using two scales one for self-efficacy and the other task value. Physics self-efficacy was measured using an adapted 5-item scale from the science motivation questionnaire (Glynn, Taasoobshirazi, \& Brickman, 2009). The students responded to the items on a 5-point Likert scale ranging from 0 (never) to 4 (always). Sample items included "I am confident I will do well in the Physics tests" and "I believe I can master physics knowledge and skills". Task value was measured using an adapted 6 -item scale $(\alpha=$ .90) from the Motivated Strategies for Learning Questionnaire (MSLQ; Pintrich, 1991). Items were rated on a 7-point Likert scale ranging from 1 (not at all true) to 7 (very true) with sample items including "I think I will be able to use what I learn in this physics in other subjects, " and "I like the subject matter of physics."

\section{Data analysis}

The correlations between the study variables were determined using the Pearson product-moment correlation coefficient in SPSS version 25.

To test for gender variations across the study variables, independent samples $t$ tests were conducted using SPSS version 25. Cohen's $d$ effect sizes for significant differences were also calculated (Cohen, 1988). Following Cohen's recommendations, effect sizes were interpreted as small if $\leq .20$, medium if $.21 \leq d \leq .50$ or high if $.51 \leq$ $d \leq .80$.

The third hypothesis about the structural model was tested using structural equation modeling (SEM). SEM was chosen for this purpose because of its relative ability to examine relationships between multiple latent variables in a single model by combining features of both path analysis and confirmatory factor analysis (CFA) (Kline, 2011). This made it possible to assess both direct and indirect relationships between latent variables within a single model.

To proceed with SEM, we first conducted data screening to ensure it was suitable for SEM. Data were mainly screened for missing values, outliers, univariate and multivariate normality, multicollinearity and sample size requirements (Kline, 2011). The sample size of 375 used in the study was considered adequate given suggestions by $\mathrm{Hu}$ and Bentler (1999) about sample sizes greater than 250 for SEM analysis. Because of the presence of some missing values, the full information maximum likelihood (FIML) estimator was used in dealing with missing data as it is more reliable compared to other approaches like list-wise deletion. The percentages of missing values for each item were less than $2 \%$; hence, they were not considered a significant threat to the results of the analysis process. The inspection of box plots showed no outliers. However, most of the item distributions were non-normal indicating both univariate and possibly multivariate non-normality which then dictated the use of maximum likelihood estimation with robust standard errors during the analyses as it is robust to non-normality. The zero-order correlations between the different items for each variable were all $<.85$, which indicates the absence of multicollinearity in the variables.

Before carrying out SEM to test the hypothesised mediation models, we initially tested the measurement model through a CFA. The rationale for CFA was to confirm the hypothesised measurement model (i.e. that the items used to measure the different variables contributed significantly to doing so). The latent variables obtained from CFA would be free of measurement error and would hence increase the accuracy of results from the tested structural model. CFA and general SEM were conducted using Mplus 7.4 (Muthen \& Muthen, 2010). One of the items with factor loadings less than .40 was removed to improve model fit (Matsunaga, 2010). Using the latent variables obtained from CFA, the hypothesised partial and full mediation models were tested for the significance of both direct paths and indirect paths from perceived teacher autonomy support to learning-related boredom and only indirect paths through cognitive appraisals.

Following suggestions by $\mathrm{Hu}$ and Bentler (1999) and Schreiber, Nora, Stage, Barlow, and King (2006), the 
model was deemed an adequate fit if the chi-square value $\chi^{2}$ was not significant and/or the $\chi^{2} / d f<5$; Comparative Fit Index (CFI) and Tucker-Lewis Index (TLI) were $\geq .90$; and the root mean square error of approximation (RMSEA) and the standardised root mean residual (SRMR) were $\leq 0.10$. To compare to the two nested models (partial or full), we conducted a robust chi-square difference test with adjusted mean and variance statistics (Asparouhov \& Muthén, 2006) as recommended by Pavlov, Shi, and Maydeu-Olivares (2020).

\section{Results}

\section{Correlations between the study variables}

All correlations between the study variables were significant (see Table 1). Perceived teacher autonomy support was positively correlated to both task value and selfefficacy and negatively associated with boredom during physics learning. There was a positive correlation between self-efficacy and task value, both of which were negatively correlated with boredom during physics learning.

\section{Gender differences}

Females reported significantly greater value to learning physics than males $t(281.41)=3.26, p<.05, d=.36$. There were no statistically significant gender differences among the other study variables (see Table 2).

\section{Mediation effects of cognitive appraisals}

On testing the measurement model consisting of four latent variables (perceived teacher's autonomy support, task value, self-efficacy and boredom), all factor loadings of the items were significant with $p<.001$. However, following a confirmatory factor analysis (CFA), we excluded one item (I feel able to share my feelings with my physics teacher) that had a factor loading less than .40 . Overall, results from the final CFA showed an acceptable fit for the model with: $\chi^{2}=787.85, d f=588, \chi^{2} / d f=$ $1.34, p<.01$; RMSEA $=.03$, C.I. $=.024-.035$ at $90 \%$; CFI $=.95 ; \mathrm{TLI}=.95$ and SRMR $=.05$.

We tested both a full and partial mediation model. Both models consisted of four latent variables, that is perceived teacher autonomy support as the predictor

Table 2 Descriptive statistics and t-statistics for gender differences among the study variables

\begin{tabular}{lllll}
\hline Variables & Males & Females & Test & $\boldsymbol{p}$ \\
& $\mathbf{M}(\mathrm{SD})$ & $\mathbf{M}(\mathrm{SD})$ & & \\
\hline 1. Perceived TAS & $77.71(17.88)$ & $75.81(17.67)$ & 1.00 & 0.34 \\
2. Self-efficacy & $14.70(4.33)$ & $14.97(4.00)$ & 0.58 & 0.56 \\
3. Task value & $32.11(8.11)$ & $34.83(6.77)$ & 3.26 & $<.01$ \\
4. Boredom & $23.89(10.22)$ & $25.23(10.77)$ & 1.15 & 0.25 \\
\hline
\end{tabular}

TAS teacher autonomy support. Significant difference $(p<.01)$ in boldface variable, learning-related boredom as the outcome variable and task value and self-efficacy as the mediator variables. The partial model demonstrated a more acceptable fit to the data with $\chi^{2}=825.68, d f=589, \chi^{2}$ / $d f=1.40, p<.01$; RMSEA $=.03$, C.I. $=.027-.038$ at $90 \%$; CFI $=.94 ;$ TLI $=.94$ and SRMR $=.05$. The chi-square difference test with MLMV estimator $(n=331)$ indicated that the partial mediation model presented a better fit with the data compared to the full mediation model $\left(\chi^{2}\right.$ $=17.99, d f=1, p<.001)$. The direct path coefficient $(\beta$ $=-.34, p<.001)$ from PTAS to boredom was significant. The significance of the chi-square test which implied inadequate model fit was attributed to the large sample size (Bentler \& Bonett, 1980). Chi-square statistics are sensitive to sample size and will tend to falsely reject models especially those based on large sample sizes.

Evaluation of the direct path coefficients in the model indicated perceived teacher autonomy support to positively contribute to cognitive appraisals (selfefficacy: $\beta=.57, p<.001, S E=.054$; task value: $\beta=$ $.46, p<.001, S E=.066)$ and to negatively contribute to learning-related boredom $(\beta=-.34, p<.001, S E$ $=.084$; see Fig. 3). Likewise, cognitive appraisals negatively contributed to physics learning-related boredom (self-efficacy: $\beta=-.18, p<.05, S E=.080$; task value: $\beta=-.20, p<.05, S E=.080)$ among the students. The model explained $33.4 \%$ of variation in learning-related boredom, $32.5 \%$ of variation in selfefficacy and $20.7 \%$ variation in task value. On assessment of significance of the indirect effects of perceived teacher autonomy support on learningrelated boredom, self-efficacy demonstrated greater mediation effects $(\beta=-.10, p<.05, S E=.047)$ than task value $(\beta=-.09, p<.01, S E=.038)$. The total indirect effects of cognitive appraisals were significant $(\beta=-.19, p<.05, S E=.057)$.

\section{Discussion}

Our results concerning associations between PTAS, cognitive appraisals and boredom were consistent with the CVTAE and other related studies including those involving other STEM domains. Perceived teacher autonomy support significantly and positively correlated with both self-efficacy and task value (d'Ailly, 2003; Hall \& Webb, 2014: Pekrun, 2006; Wang et al., 2017; Patall et al., 2013; Piko \& Pinczes, 2015; Liu et al., 2018). Students who reported that their teachers provided autonomy support were more likely to believe in their ability to succeed and value physics tasks. Further, students' perceived teacher autonomy support and cognitive appraisals were negatively correlated with boredom (Wang et al., 2017). Hence, the higher the students perceived their physics teachers' behaviours as autonomy-supportive, the lower 


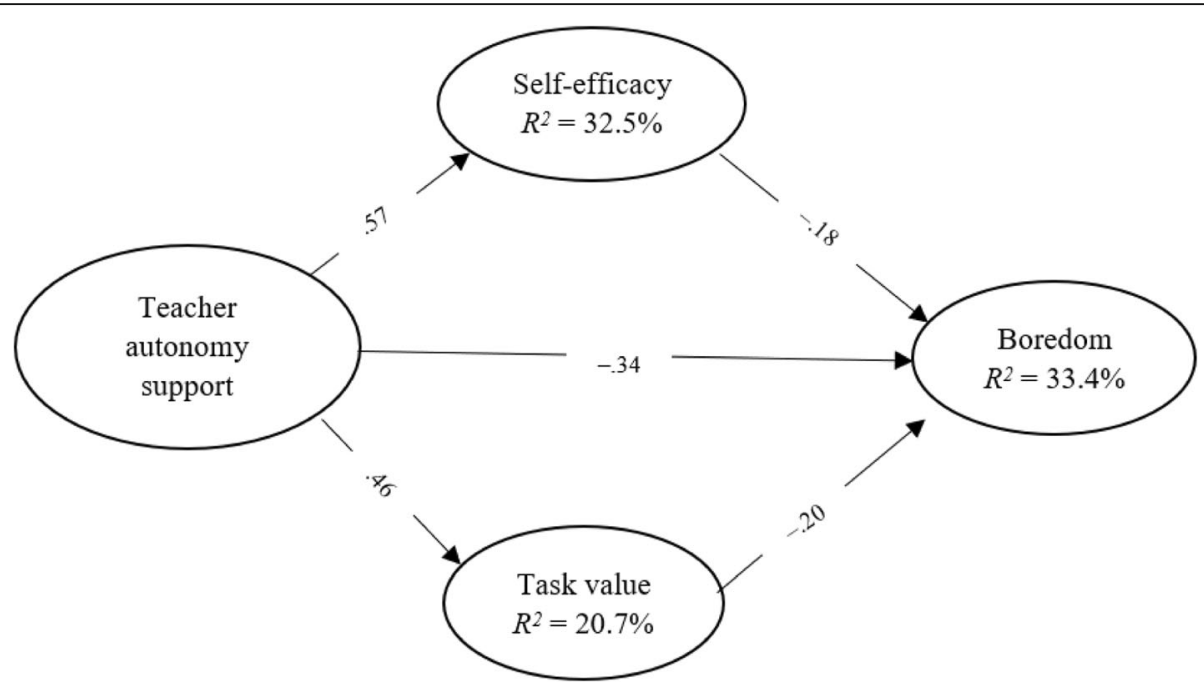

Fig. 3 Partial mediation model with latent variables showing standardised beta correlation coefficients $(\beta)$ and coefficients of determination $\left(R^{2}\right)$

the students thought of their physics learning experiences as being boring. Students who thought of themselves as being capable of succeeding in physics-related tasks were less likely to get bored while performing such tasks than those who did not believe they were capable of succeeding in such physics-related tasks. Likewise, consistent with Wang et al.'s (2017) findings, the higher the value student attached to physics-related tasks, the lower the boredom they experienced doing the tasks. The significant relation between cognitive appraisals of subjective control and value was consistent with a previous finding in mathematics among lower secondary school students in Uganda (Kiwanuka et al., 2017; Muwonge et al., 2018) and others (Bong, 2001). These findings were all in general agreement with studies using different populations and subject domains, e.g. Wang et al. (2017) among Chinese students, Pekrun et al. (2010) among German and Canadian students and Piko and Pinczes (2015) among Hungarian students demonstrating cross-cultural universality and STEM domain similarities.

Our initial interest in examining gender differences in PTAS and boredom among lower secondary students stemmed from the little research in this area. In addition to this, for all the study variables, the evidence available was contradictory and mostly based on participants from developed countries. If judgement was made based on most studies conducted within developed countries, we would have expected that females would obtain lower scores in self-efficacy (Nissen, 2019), task value and higher score on boredom (Limprecht et al., 2013) compared to males. However, our study findings and some others conducted within Uganda and Kenya indicated otherwise. The absence of gender differences in subjective control in our study although contradictory with most previous research findings was consistent with the findings of Majere et al. (2012); in Physics) among Kenyan students and Kwarikunda et al. (2020); in Physics) and Kiwanuka et al. (2017); in mathematics) among Ugandan lower secondary school students. Perhaps these findings correspond with Sikora and Pokropek (2012) that gender differences in science subjective control are less prominent in developing countries.

In this study, females rated the value of learning physics much higher than the males. This finding was consistent with Kiwanuka et al.'s (2017) earlier study in mathematics among Ugandan lower secondary students. However, it contradicted Majere et al. (2012) who found no significant gender differences in perceived usefulness for learning physics among lower secondary Kenyan students, although female scores were higher than male scores. One possible explanation could be that female students in Uganda are encouraged through the provision of opportunities (e.g. extra 1.5 points added to them when competing for government sponsorship into post-secondary institutions) to enroll in science-related career courses. In the long term, students are also motivated by the anticipated rewards of a science-career in the future. Likewise, there are more science-oriented careers where the government is keen to recruit, retain and pay scientists more the non-science-based professionals. However, this explanation in a sense may only account for the extrinsic value component and not the intrinsic value component of task value which is considered to be more important in predicting emotions (Pekrun, 2006). This minimal influence of extrinsic value may likely have a low impact on students' subsequent experiences of boredom. It is no wonder there were no significant differences between male and female students' learning-related boredom despite the differences 
noted in task value. The absence of gender differences in boredom agreed with an earlier study in mathematics (Frenzel et al., 2007a; Pekrun et al., 2011; Piko \& Pinczes, 2015). Further, our results showed that there was no significant relationship between gender and perceived teacher autonomy support. The findings contradict prior studies that noted that science teachers' behaviours during instruction unintentionally demonstrate preferential support to males by directing more questions to them, paying more attention to their questions and providing them with more feedback (Altermatt et al., 1998; Jones \& Dindia, 2004). This biased classroom attention probably resulted in low interest and increased boredom in physics activities.

Our results supported the partial mediation model in which perceived teacher autonomy support both directly and indirectly through cognitive appraisals influenced boredom. This contradicts Wang et al.'s (2017) findings of the full mediational effects of cognitive appraisals in mathematics. Hence, according to the results, boredom among students may directly be influenced by perceptions about their teacher's autonomy support and/or indirectly influenced by students' cognitive appraisals that are as a result of these perceptions. For example, students learning physics will be bored because their teacher failed to acknowledge their perspectives that negatively impacted their self-efficacy beliefs that in turn causes boredom. Further, self-efficacy proved to be a more important mediator than task value, a finding that was consistent with Wang and his colleagues' (2017) study. This observation perhaps further explains why no gender differences were found for boredom among the students. From our results, self-efficacy-in which no significant gender differences were noted-seems to be a much greater mediator and therefore a better predictor of boredom than task value.

The results of the present study present significant implications for theory, STEM education and future research. First, the results provided additional support for the cross-cultural application of the CVTAE assumptions about the mediational effects of cognitive appraisals on the relationship between teacher instructional behaviour and emotions and the nature of the relationship between the study variables. The results highlight the significance of promoting autonomy among learners through autonomy-supportive teachers' behaviours as they influence not just boredom but also cognitive appraisals that in turn influence the former. Therefore, teachers' practices may be important in helping students gain interest and build confidence in their abilities to learn physics. It also provides a basis for intervention studies that aim at regulating both cognitive appraisals and/or boredom of learners. The effects of PTAS are not just limited to boredom but have many other influences through cognitive appraisals on students' positive emotions and subsequently motivation, use of learning strategies, engagement and achievement in other STEM disciplines (Black \& Deci, 2000; Liu et al., 2018). Hence, it is evident that the importance of PTAS goes beyond solving problems of boredom in a physics classroom to solving several other emotional, motivational and achievement problems of STEM education in secondary school. The significant role played by cognitive appraisals as mediators between environmental influences and emotions calls for practices that directly or indirectly target the improvement of these cognitive appraisals as they play a central role. Further, the fact that self-efficacy was found to be a greater mediator compared to task value suggests that intervention efforts aimed at reducing or eliminating boredom should focus more on ways to improve students' self-efficacy. However, efforts to enhance task value for physics cannot be ignored as they also have an important contribution to the development of motivation, i.e. for one to persist and remain focused on a task they find cognitively manageable, they should also find it valuable. The observation that females valued physics more than the males was an indication that probably incentives allowed by government policy and the scientific work environment may be a good driving force to promote females' involvement in STEM. However, the fact that this difference did not transcend into a significant gender difference in boredom implied that external motivators may not result in significant learning-related emotional changes. Further, the absence of gender differences in self-reported self-efficacy and boredom disconfirmed the common public belief that female students in Ugandan secondary schools are less confident in their physics abilities than the males. This absence of gender differences in self-efficacy and boredom also disconfirms the commonly reported justification for the gender-gap in physics achievement and now raises more questions for researchers as to what else could be the cause for these differences. Future studies should examine how the financial state or the socio-cultural beliefs and practices influence STEM achievement in either gender.

We adopted standardised measures for the study and we had a relatively large sample of students. However, the present study has some limitations. First, the study sample was selected from only one district of Uganda. This limits the generalizability of the findings to other students in Uganda. The sample also included participants with a broad age range (i.e. 13-19 years). This is because, for various reasons, some children either start school at different ages or repeat classes and/or drop out of school and later return. Such a group of learners may significantly differ in their cognitive and emotional developments and therefore their learning and/or 
achievement. It is therefore important to consider what implications this wide age range may have when interpreting the study results. Second, the use of self-reports may introduce bias to the results due to socialdesirability effects. Hence, future research needs to also consider obtaining qualitative data through observations to cater for biases resulting from these self-reports. Third, although science teachers in most African developing countries often lack adequate training in effective pedagogical approaches to combat boredom, their inability to perform effectively may also be influenced low job satisfaction and low motivation stemming from poor salaries and the work environment that is often highly demanding with high teacher-student ratios, and therefore heavy workloads that may limit their performance in the classroom (Bennell \& Akyeampong, 2007). Perhaps future studies should examine the extent to which how such stressful work environments influence teacher's classroom behaviour and how this results in boredom among students. The present study did not examine the influence of the study variables on achievement. Hence, it still remains unclear why wide gender differences are observed in students' science achievement at national examinations and yet such differences were not observed in the study variables. Perhaps future studies need to examine other possible causes of differences in science achievement between boys and girls.

\section{Conclusion}

This study's findings provide support for the CVTAE assumptions about the nature of the relationship between the study variables. In particular, perceived teacher autonomy support positively correlated with the cognitive appraisals and negatively with boredom. The effects of perceived teacher autonomy support on boredom were found to be both direct and indirect through cognitive appraisals. However, self-efficacy exhibited greater mediational effects than task value. Contrary to most studies, females reported higher task value than males, and no other gender differences were observed.

\section{Abbreviations \\ CVTAE: Control Value Theory of Achievement Emotions; PTAS: Perceived teacher autonomy support; STEM: Science, Technology, Engineering, and Mathematics; UNEB: Uganda National Examinations Board; LCQ: Learning Climate Questionnaire; LRBS: Learning-Related Boredom Scale; MLSQ: Motivated Strategies for Learning Questionnaire; SPSS: Statistical Package for Social Scientists; SEM: Structural equation modeling; CFA: Confirmatory factor analysis; FIML: Full information maximum likelihood; CFI: Comparative Fit Index; TLI: Tucker-Lewis Index; RMSEA: Root mean square error of approximation; SRMR: Standardised root mean residual}

\section{Acknowledgements}

The authors would like to thank the teachers and students who contributed to the accomplishment of the study. The second author thanks the KAAD for funding her doctoral studies at the University of Potsdam. The authors also thank Anton Schneider for proofreading the final version of the manuscript.

\section{Authors' contributions}

ME and KD conceptualized the study and drafted the manuscript. CMM, JS and US made significant contributions to the study design and critically reviewed the manuscript. ME, KD, CMM and JS collected the data. ME, KD and CCM analyzed the data. JS and US provided overall supervision of the study. All authors read and approved the final version of the manuscript.

\section{Funding}

The authors received no external funding for this research project.

\section{Availability of data and materials}

The datasets used and/or analyzed during the current study are available from the corresponding author on reasonable request.

\section{Competing interests}

The authors declare that they have no competing interests.

\section{Author details}

${ }^{1}$ Department of Educational Foundations and Psychology, Faculty of Science, Mbarara University of Science and Technology, P. O. Box 1410, Mbarara, Uganda. ${ }^{2}$ Faculty of Human Sciences, Department of Educational Sciences, University of Potsdam, Karl-Liebknecht-str. 24/25 House14, 14476 Potsdam, Germany. ${ }^{3}$ Department of Psychology, University of Konstanz, 78567 Konstanz, Germany.

Received: 3 June 2020 Accepted: 18 January 2021

Published online: 29 March 2021

\section{References}

Acee, T. W., Kim, H., Kim, H. J., Kim, J., Chu, H. R., Kim, M., et al. (2010). Academic boredom in under- and over-challenging situations. Contemporary Educational Psychology, 35, 17-27. https://doi.org/10.1016/j.cedpsych.2009.08. 002

Ahmed, W., Minnaert, A., van der Werf, G., \& Kuyper, H. (2010). Perceived social support and early adolescents' achievement: The mediational roles of motivational beliefs and emotions. Journal of Youth and Adolescence, 39, 3646. https://doi.org/10.1007/s10964-008-9367-7.

Altermatt, E. R., Jovanovic, J., \& Perry, M. (1998). Bias or responsivity? Sex and achievement-level effects on teachers' classroom questioning practices. Journal of Educational Psychology, 90(3), 516-527. https://doi.org/10.1037/ 0022-0663.90.3.516.

Arvanitis, R., Waast, R., \& Gaillard, J. (2000). Science in Africa: A bibliometric panorama using PASCAL database. Scientometrics, 47(3), 457-473.

Asparouhov, T., \& Muthén, B. (2006). Robust chi-square difference testing with mean and variance adjusted test statistics (Mplus Web Notes No. 10) Retrieved from http://www.statmodel.com/download/webnotes/webnote10. pdf

Bandura, A. (1977). Self-efficacy: Toward a unifying theory of behavioural change. Psychological Review, 84(2), 191-215.

Becker, J. R. (1981). Differential treatment of females and males in mathematics classes. Journal for Research in Mathematics Education, 12(1), 40-53 https:// www.jstor.org/stable/748657.

Bennell, P., \& Akyeampong, K. (2007). Teacher motivation in sub-Saharan Africa and South Asia, (vol. 71). Department for International Development.

Bentler, P. M., \& Bonett, D. G. (1980). Significance tests and goodness of fit in the analysis of covariance structures. Psychological Bulletin, 88(3), 588-606.

Black, A. E., \& Deci, E. L. (2000). The effects of instructors' autonomy support and students' autonomous motivation on learning organic chemistry: A selfdetermination theory perspective. Science Education, 84(6), 740-756.

Black, T. R., Atwaru-Okello, D., Kiwanuka, J., Serwadda, D., Birabi, O., Malinga, F., Rodd, A. (1998). Science education in Uganda: Progress and possibilities. International Journal of Science Education, 20(2), 239-252. https://doi.org/10. 1080/0950069980200208.

Bong, M. (2001). Between-and within-domain relations of academic motivation among middle and high school students: Self-efficacy, task value, and achievement goals. Journal of Educational Psychology, 93(1), 23-24.

Bwire, A., Huang, Y., Masingila, J. O., \& Ayot, H. (2011). Proceedings of the 2nd International Conference on Education. Nairobi: Kenyatta University.

Cohen, J. (1988). Statistical power analysis for the behavioral sciences, (2nd ed., ). Lawrence Erlbaum. 
d'Ailly, H. (2003). Children's autonomy and perceived control in learning: A model of motivation and achievement in Taiwan. Journal of Educational Psychology, 95(1), 84-96. https://doi.org/10.1037/0022-0663.95.1.84.

Daschmann, E. C., Goetz, T., \& Stupnisky, R. H. (2011). Testing the predictors of boredom at school: Development and validation of the precursors to boredom scales. British Journal of Educational Psychology, 81(3), 421-440. https://doi.org/10.1348/000709910X526038.

Deci, E. L., Ryan, R. M., \& Williams, G. C. (1996). Need satisfaction and the self-regulation of learning. Learning and Individual Differences, 8(3), 165183.

Eccles, J. (2011). Gendered educational and occupational choices: Applying the Eccles et al. model of achievement-related choices. International Journal of Behavioral Development, 35(3), 195-201. https://doi.org/10.1177/ 0165025411398185

Eccles, J. S., \& Wigfield, A. (1995). In the mind of the actor: The structure of adolescents' achievement task values and expectancy-related beliefs. Personality and Social Psychology Bulletin, 21(3), 215-225.

Education Policy and Planning Department (2017). Education and Sports Sector Statistical Abstract. Uganda: Ministry of Education and Sports.

Else-Quest, N. M., Hyde, J. S., \& Linn, M. C. (2010). Cross-national patterns of gender differences in mathematics: A meta-analysis. Psychological Bulletin 136(1), 103-127. https://doi.org/10.1037/a0018053.

Fisher, D. L., Fraser, B. J., \& Rickards, T. W. (1997, March 24-28). Gender and cultural differences in teacher-student interpersonal behavior [paper presentation]. American Educational Research Association Annual Meeting, Chicago.

Fogelman, K. (1976). Bored eleven-year-olds. The British Journal of Social Work, 6(2), 201-211 https://www.jstor.org/stable/23693693.

Frenzel, A. C., Pekrun, R., \& Goetz, T. (2007a). Girls and mathematics—A "hopeless" issue? A control-value approach to gender differences in emotions towards mathematics. European Journal of Psychology of Education, 22(4), 497-514 https://www.jstor.org/stable/23421520.

Frenzel, A. C., Pekrun, R., \& Goetz, T. (2007b). Perceived learning environment and students' emotional experiences: A multilevel analysis of mathematics classrooms. Learning and Instruction, 17(5), 478-493. https://doi.org/10.1016/j. learninstruc.2007.09.001.

Gherasim, L. R., Butnaru, S., \& Mairean, C. (2013). Classroom environment, achievement goals, and maths performance: Gender differences. Educational Studies, 39(1), 1-12. https://doi.org/10.1080/03055698.2012.663480.

Glynn, S. M., Taasoobshirazi, G., \& Brickman, P. (2009). Science motivation questionnaire: Construct validation with nonscience majors. Journal of Research in Science Teaching, 46(2), 127-146. https://doi.org/10.1002/tea. 20267.

Goan, S., Cunningham, A., \& Carroll, C. (2006). Degree completions in areas of national need, 1996-97 and 2001-02. National Centre for Education Statistics Retrieved from https://eric.ed.gov/?id=ED492571.

Goetz, T., Bieg, M., Ludtke, O., Pekrun, R., \& Hall, N. C. (2013). Do girls really experience more anxiety in mathematics? Psychological Science, 24(10), 20792087.

Goetz, T., Cronjager, H., Frenzel, A. C., Ludtke, O., \& Hall, N. C. (2010). Academic self-concept and emotion relations: Domain specificity and age effects. Contemporary Educational Psychology, 35(1), 44-58. https://doi.org/10.1016/j. cedpsych.2009.10.001.

Goetz, T., Frenzel, A. C., Hall, N. C., \& Pekrun, R. (2008). Antecedents of academic emotions: Testing the internal/external frame of reference model for academic enjoyment. Contemporary Educational Psychology, 33(1), 9-33.

Goetz, T., Ludtke, O., Nett, U. E., Keller, M. M., \& Lipnevich, A. A. (2013). Characteristics of teaching and students' emotions in the classroom: Investigating differences across domains. Contemporary Educational Psychology, 38(4), 383-394.

Goetz, T., Pekrun, R., Hall, N., \& Haag, L. (2006). Academic emotions from a socialcognitive perspective: Antecedents and domain specificity of students' affect in the context of Latin instruction. British Journal of Educational Psychology, 76, 289-308.

Goh, S. C., \& Fraser, B. J. (1998). Teacher interpersonal behaviour, classroom environment and student outcomes in primary mathematics in Singapore. Learning Environments Research, 1, 199-229.

Gunderson, E. A., Ramirez, G., Levine, S. C., \& Beilock, S. L. (2012). The role of parents and teachers in the development of gender-related math attitudes. Sex Roles, 66, 153-166.
Haager, J. S., Kuhbandner, C., \& Pekrun, R. (2016). To be bored or not to be bored-How task-related boredom influences creative performance. The Journal of Creative Behavior, 52(4), 297-304. https://doi.org/10.1002/jocb.154.

Hall, N., \& Webb, D. (2014). Instructors' support of student autonomy in an introductory physics course. Physical Review Physics Education Research, 10(2), Article, 020116. https://doi.org/10.1103/PhysRevSTPER.10.020116.

Hu, L. T., \& Bentler, P. M. (1999). Cutoff criteria for fit indexes in covariance structure analysis: Conventional criteria versus new alternatives. Structural Equation Modeling: A Multidisciplinary Journal, 6(1), 1-55. https://doi.org/10. 1080/10705519909540118.

Hyde, J. S., Fennema, E., Ryan, M., Frost, L. A., \& Hopp, C. (1990). Gender comparisons of mathematics attitudes and affect: A meta-analysis. Psychology of Women Quarterly, 14, 299-324.

Jones, S. M., \& Dindia, K. (2004). A meta-analytic perspective on sex equity in the classroom. Review of Educational Research, 74(4), 443-471.

Joussemet, M., Koestner, R., Lekes, N., \& Houlfort, N. (2004). Introducing uninteresting tasks to children: A comparison of the effects of rewards and autonomy support. Journal of Personality, 72(1), 139-166.

Kanevsky, L., \& Keighley, T. (2003). To produce or not to produce? Understanding boredom and the honor in underachievement. Roeper Review, 26(1), 20-28. https://doi.org/10.1080/02783190309554235.

Kiwanuka, H. N., Van Damme, J., Van Den Noortgate, W., Anumendem, D. K., \& Namusisi, S. (2015). Factors affecting Mathematics achievement of first-year secondary school students in Central Uganda. South African Journal of Education, 35(3), Article, 1106. https://doi.org/10.15700/saje.v35n3a1106.

Kiwanuka, H. N., Van Damme, J., Van Den Noortgate, W., Anumendem, D. K., Vanlaar, G., Reynolds, C., \& Namusisi, S. (2017). How do student and classroom characteristics affect attitude towards math? A multivariate multilevel analysis. School Effectiveness and School Improvement, 28(1), 1-21. https://doi.org/10.1080/09243453.2016.1201123.

Kline, R. B. (2011). Principles and practice of structural equation modeling, (3rd ed., ). The Guilford Press.

Krejcie, R. V., \& Morgan, D. W. (1970). Determining sample size for research activities. Educational and Psychological Measurement, 30(3), 607-610.

Kwarikunda, D., Schiefele, U., Ssenyonga, J., \& Muwonge, C. M. (2020). The relationship between motivation for, and interest in, learning physics among lower secondary school students in Uganda. African Journal of Research in Mathematics, Science and Technology Education. https://doi.org/10.1080/ 18117295.2020 .1841961$.

Larson, R. W., \& Richards, M. H. (1991). Boredom in the middle school years: Blaming schools versus blaming students. American Journal of Education, 99(4), 418-443. https://doi.org/10.1086/443992.

Lazarides, R., \& Buchholz, J. (2019). Student-perceived teaching quality: How is it related to different achievement emotions in mathematics classrooms? Learning and Instruction, 61, 45-59. https://doi.org/10.1016/j.learninstruc.2019. 01.001.

Lichtenfeld, S., Pekrun, R., Stupnisky, R. H., Reiss, K., \& Murayama, K. (2012). Measuring students' emotions in the early years: the achievement emotions questionnaire-elementary school (AEQ-ES). Learning and Individual Differences, 22(2), 190-201.

Limprecht, S., Janko, T., \& Glaser-Zikuda, M. (2013). Achievement emotions of boys and girls in physics instruction: Does a portfolio make a difference. Orbis Scholae, 7(2), 43-66.

Liu, R., Zhen, R., Ding, Y., Liu, Y., Wang, J., Jiang, R., \& Xu, L. (2018). Teacher support and math engagement: Roles of academic self-efficacy and positive emotions. Educational Psychology, 38(1), 3-16. https://doi.org/10.1080/ 01443410.2017 .1359238

Ma, X., \& Cartwright, F. (2003). A longitudinal analysis of gender differences in affective outcomes in mathematics during middle and high school. School Effectiveness and School Improvement, 14(4), 413-439.

Majere, I. S. M., Role, E., \& Makewa, L. N. (2012). Gender disparities in self-concept, attitude and perception in physics and chemistry. Atlas Journal of Science Education, 2(1), 61-69.

Matsunaga, M. (2010). How to factor-analyze our data right: Do's, don'ts and how to's. International Journal of Psychological Research, 3(1), 97-110.

Mulligan, K., \& Scherer, K. R. (2012). Toward a working definition of emotion. Emotion Review, 4(4), 345-357. https://doi.org/10.1177/1754073912445818.

Muthen, L. K., \& Muthen, B. O. (2010). Mplus user's guide, (6th ed., ). Los Angeles Muthén and Muthén.

Muwonge, C. M., Ssenyonga, J., \& Kwarikunda, D. (2018). Cognitive appraisals, achievement emotions, and motivation towards learning mathematics 
among lower secondary students. African Journal of Research in Mathematics, Science and Technology Education, 22(2), 243-253. https://doi.org/10.1080/ 18117295.2018.1487907.

Nissen, J. M. (2019). Gender differences in self-efficacy states in high school physics. Physical Review Physics Education Research, 15(1), Article 013102.

Nosek, B. A., Banaji, M. R. \& Greenwald, A. G. (2002). Math = Male, Me = Female, Therefore Math $\neq$ Me. Journal of Personality and Social Psychology, 83(1), 44-59.

Opolot-Okurut, C. (2005). Student attitudes towards Math in Ugandan secondary schools. African Journal of Research in Mathematics Science and Technology Education, 9(2), 167-174.

Painter, J. (2011). Autonomy, competence, and intrinsic motivation in science education: A self-determination theory perspective (Unpublished doctoral dissertation). University of North Carolina at Chapel Hill.

Patall, E. A., Dent, A. L., Oyer, M., \& Wynn, S. R. (2013). Student autonomy and course value: The unique and cumulative roles of various teacher practices. Motivation and Emotion, 37, 14-32. https://doi.org/10.1007/ s1 1031-012-9305-6.

Pavlov, G., Shi, D., \& Maydeu-Olivares, A. (2020). Chi-square difference tests for comparing nested models: An evaluation with non-normal data. Structural Equation Modeling: A Multidisciplinary Journal. https://doi.org/10.1080/ 10705511.2020.1717957

Pekrun, R. (2006). The control-value theory of achievement emotions: Assumptions, corollaries, and implications for educational research and practice. Educational Psychology Review, 18(4), 315-341.

Pekrun, R., Goetz, T., Daniels, L. M., Stupinsky, R. H., \& Perry, R. P. (2010). Boredom in achievement settings: Exploring control-value antecedents and performance outcomes of a neglected emotion. Journal of Educational Psychology, 102(3), 531-549.

Pekrun, R., Goetz, T., Frenzel, A. C., Barchfeld, P., \& Perry, R. P. (2011). Measuring emotions in students' learning and performance: The Achievement Emotions Questionnaire (AEQ). Contemporary Educational Psychology, 36(1), 36-48.

Pekrun, R., Goetz, T., Titz, W., \& Perry, R. P. (2010). Academic Emotions in Students' Self-Regulated Learning and Achievement: A Program of Qualitative and Quantitative Research. Educational Psychologist, 37(2), 91-105. https://doi.org/ 10.1207/S15326985EP3702_4.

Pekrun, R., \& Stephens, E. J. (2010). Achievement emotions: A control-value approach. Social and Personality Psychology Compass, 4(4), 238-255. https:// doi.org/10.1111/j.1751-9004.2010.00259.x.

Picho, K., \& Stephens, J. M. (2012). Culture, context, and stereotype threat: A comparative analysis of young Ugandan women in coed and single-sex schools. The Journal of Educational Research, 105(1), 52-63. https://doi.org/10. 1080/00220671.2010.517576

Piko, B., \& Pinczes, T. (2015). Autonomy support or direct control? High school students' experience of their teacher's behaviour. European Journal of Mental Health, 10, 106-117.

Pintrich, P. R., Smith, D. A. F., Garcia, T., \& McKeachie, W. J. (1991). A manual for the use of the Motivated Strategies for Learning Questionnaire (MSLQ). https://eric.ed.gov/?id=ED338122.

Pouris, A., \& Pouris, A. (2009). The state of science and technology in Africa (2000-2004): A scientometric assessment. Scientometrics, 79(2), 297-309. https://doi.org/10.1007/s11192-009-0419-X.

Putwain, D. W., Pekrun, R., Nicholas, L. J., Symes, W., Becker, S., \& Marsh, H. W. (2018). Control-value appraisals, enjoyment, and boredom in mathematics: A longitudinal latent interaction analysis. American Education Research Journal, 55(6), 1-30. https://doi.org/10.3102/0002831218786689.

Reid, N., \& Skryabina, E. A. (2003). Gender and physics. International Journal of Science Education, 25(4), 509-536. https://doi.org/10.1080/ 0950069022000017270.

Robinson, W. P. (1975). Boredom at school. British Journal of Educational Psychology, 45(2), 141-152. https://doi.org/10.1111/j.2044-8279.1975.tb03239.x.

Ryan, R. M., \& Grolnick, W. S. (1986). Origins and pawns in the classroom: Selfreport and projective assessments of individual differences in children's perceptions. Journal of Personality and Social Psychology, 50(3), 550-558.

Samuelsson, M., \& Samuelsson, J. (2016). Gender differences in boys' and girls' perception of teaching and learning mathematics. Open Review of Educational Research, 3(1), 18-34. https://doi.org/10.1080/23265507.2015. 1127770.

Sanchez-Rosas, J., \& Esquivel, S. (2016). Instructional teaching quality, task value, self-efficacy, and boredom: A model of attention in class. Revista de Psicología, 25(2), 1-20.
Schreiber, J. B., Nora, A., Stage, F. K., Barlow, E. A., \& King, J. (2006). Reporting structural equation modeling and confirmatory factor analysis results: A review. The Journal of Educational Research, 99(6), 323-338. https://doi.org/10. 3200/JOER.99.6.323-338.

Schubert, D. S. (1978). Creativity and coping with boredom. Psychiatric Annals, 8(3), 46-54. https://doi.org/10.3928/0048-5713-19780301-06.

Seba, J. M., Ndunguru, P. A., \& Mkoma, S. L. (2013). Secondary school students' attitudes towards Chemistry and Physics subjects in Tarime-Mara, Tanzania. Tanzania Journal of Natural and Applied Sciences, 4(2), 642-647.

Sierens, E., Soenens, B., Luyckx, K., Vansteenkiste, M., Goossens, L., \& Beyers, W. (2010). Dynamics of perceived teacher autonomy support and structure: Longitudinal associations with students' autonomous motivation and selfregulated learning. [Unpublished doctoral dissertation]. Leuven, Belgium: Katholieke University.

Sikora, J., \& Pokropek, A. (2012). Gender segregation of adolescent science career plans in 50 countries. Science Education, 96(2), 234-264. https://doi.org/10. 1002/sce.20479.

Skinner, E. A. (1996). A guide to constructs of control. Journal of Personality and Social Psychology, 7(3), 549-570.

Tennant, J. E., Demaray, M. K., Malecki, C. K., Terry, M. N., Clary, M., \& Elzinga, N. (2014). Students' ratings of teacher support and academic and socialemotional well-being. School Psychology Quarterly, 30(4), 494-512. https://doi. org/10.1037/spq0000106.

Tucker, C. M. V., Zayco, R. A., Herman, K. C., Reinke, W. M., Trujillo, M., Carraway, K. ... Ivery, P. D. (2002). Teacher and child variables as predictors of academic engagement among low-income African American children. Psychology in the Schools, 39(4), 477-489.

Tze, V. M., Daniels, L. M., \& Klassen, R. M. (2015). Evaluating the relationship between boredom and academic outcomes: A meta-analysis. Educational Psychology Review, 28(1), 119-144.

Tze, V. M., Klassen, R. M., \& Daniels, L. M. (2014). Patterns of boredom and its relationship with perceived autonomy support and engagement. Contemporary Educational Psychology, 39(3), 175-187. https://doi.org/10.1016/ j.cedpsych.2014.05.001.

Uganda National Examinations Board (2015). Report on work of candidates Uganda Certificate of Education 2014. Kampala UNEB.

Uganda National Examinations Board (2016). Report on work of candidates Uganda Certificate of Education 2015. Kampala UNEB.

Uganda National Examinations Board (2017). Report on work of candidates Uganda Certificate of Education 2016. Kampala UNEB.

Uganda National Examinations Board (2018). Report on work of candidates Uganda Certificate of Education 2017. Kampala UNEB.

Vansteenkiste, M., Sierens, E., Goossens, L., Soenens, B., Dochy, F., Mouratidis, A., ... Beyers, W. (2012). Identifying configurations of perceived teacher autonomy support and structure: Associations with self-regulated learning, motivation, and problem behaviour. Learning and Instruction, 22(6), 431-443. https://doi.org/10.1016/j.learninstruc.2012.04.002.

Wang, J., Liu, R. D., Ding, Y., Xu, L., Liu, Y., \& Zhen, R. (2017). Teacher's autonomy support and engagement in Math: Multiple mediating roles of self-efficacy, intrinsic value, and boredom. Frontiers in Psychology, 8, Article 1006. https:// doi.org/10.3389/fpsyg.2017.01006

Williams, G. C., \& Deci, E. L. (1996). Internalization of biopsychosocial values by medical students: A test of self-determination theory. Journal of Personality and Social Psychology, 70(4), 767-779. https://psycnet.apa.org/doi/10.1037/ 0022-3514.70.4.767.

\section{Publisher's Note}

Springer Nature remains neutral with regard to jurisdictional claims in published maps and institutional affiliations. 